\title{
What determines UN approval of greenhouse gas emission reduction projects in developing countries?
}

\author{
An analysis of decision making on the CDM Executive Board
}

\author{
Florens Flues • Axel Michaelowa • \\ Katharina Michaelowa
}

Received: 6 June 2008 / Accepted: 7 October 2009 / Published online: 23 October 2009

(C) Springer Science+Business Media, LLC 2009

\begin{abstract}
The Clean Development Mechanism (CDM), established by the Kyoto protocol, can generate substantial rents for project participants via the sale of Certified Emission Reductions. For this reason, supposedly technical decisions about the approval of CDM methodologies and about the registration of projects may be driven by benefits to specific countries or interest groups. Our econometric analysis of data for about 250 methodologies and about 1000 projects discussed by the CDM Executive Board (EB) so far, suggests that indeed, along with formal quality criteria, political-economic variables determine the final EB decision.
\end{abstract}

Keywords International climate policy · CDM · Political economy · Rational choice · International organization

JEL Classification D73 $\cdot$ O19 $\cdot$ Q56

\section{Introduction}

The CDM Executive Board (EB) is an institution defined by the Kyoto Protocol to the UN Framework Convention on Climate Change (UNFCCC). Its 20 members and alternates are elected by the UNFCCC Conference of the Parties and meet about once a month to register individual projects to be carried out in the framework of the Clean Development Mechanism (CDM). Moreover, EB members are responsible for the approval of methodologies used to assess the "additionality" of current and future projects and to calculate as well as monitor their emission reductions. As defined by the Conference of the Parties (UNFCCC 2002), "a project activity is additional, if anthropogenic emissions of greenhouse gases by sources are reduced below those that would have occurred in the absence of the registered CDM project activity".

F. Flues $(\bowtie) \cdot$ A. Michaelowa $\cdot$ K. Michaelowa

Center for Comparative and International Studies (CIS), University of Zurich, Hirschengraben 56, 8001

Zurich, Switzerland

e-mail: florens.flues@pw.uzh.ch 
As the CDM allows industrialized countries to receive Certified Emission Reductions (CERs) from projects in developing countries, the assessment of additionality is vital to determine whether emission reductions through these projects would not have happened without the CDM as well. The approval of non-additional projects leads to benefits for the investor in the industrialized and/or in the developing country concerned (depending on resource flows agreed between these partners), to the detriment of global protection against climate change. We ask whether this conflict between global and country specific benefits (i.e., greenhouse gas mitigation versus revenues from CER sales) becomes visible in terms of the registration of projects and the approval of methodologies by the EB.

To assess this question, we draw upon the Public Choice literature on international organizations, as initially developed by Frey $(1984,1997)$, Vaubel $(1986,2006)$, and Vaubel and Willet (1991), which is in turn related to more general questions of collective action (Sandler 1992; Sandler and Hartley 2001). On the basis of these early works, a large literature has developed in recent years, and the role of special interests has been analyzed in the context of many international organizations, most prominently the IMF and the World Bank. Usually, this role is found to be substantial. For example, several authors find that the membership of a developing country on the UN security council not only significantly increases the aid flows it receives from the U.S., but also the credits it receives from the IMF and World Bank (Kuziemko and Werker 2006; Dreher et al. 2009a, 2009b). These effects appear to be driven by some sort of vote buying. Similarly, membership on the World Bank's Board of Executive Directors is found to approximately double funding from the IBRD (Kaja and Werker 2009). However, Public Choice analysis of environmental decision making is so far largely restricted to the national level. In their comprehensive review of studies on the political economy of environmental policies, Oates and Portney (2003) find that both social welfare and interest-related variables have an impact on regulatory outcomes.

With rising concerns about climate change, the general literature on global greenhouse gas mitigation has also expanded dramatically. The UNFCCC, as the major policy regime covering the current Kyoto Protocol as well as its successor after 2012 has, however, been largely neglected by academics. This is true especially when it comes to empirical evidence on its internal functioning. From a practical perspective, more knowledge might help to design more effective climate policy treaties in the future. Theoretically, it is of interest whether the results from the existing literature carry over to this newly established and unique institution.

Based on nearly 1000 projects and 250 methodologies discussed by the EB until October 2007, we ask what determines EB decision making. More specifically, we want to assess whether purely technical aspects of the emission reduction of projects or methodologies dominate, or whether member countries' special interests (including the interests of lobbies within these countries) have any major influence, too. We therefore closely examine the relevance of recommendations by specialized technical committees on the one hand, and the role of EB members' nationality and other strategic or interest-related variables on the other hand. The latter include the role of the World Bank as a major participant in the CDM business, the impact of change over time due to increasing numbers of methodologies and projects, and the degree of transparency of the EB decision-making process.

In Sect. 2, our theoretical ideas will be outlined in more detail. This will allow us to motivate our hypotheses. Section 3 then discusses the data and the estimation strategy we use for our econometric analysis. Section 4 presents the results. Finally, Sect. 5 derives first conclusions and policy recommendations for the further institutional development of the UNFCCC Secretariat and its CDM Executive Board. 


\section{Determinants of EB decision making: a brief theoretical foundation}

\subsection{Decision making in boards of international organizations and in national environmental bureaucracies}

Recent studies have shown that membership on boards of international organizations can yield more favorable outcomes for the countries represented. Kaja and Werker (2009) find that membership on the World Bank's board of governors significantly increases funding by the IBRD. Even though the UNFCCC and the World Bank differ strongly in terms of setup and organization, we focus on potential similarities here. Decisions on funding by the IBRD and decisions by the EB on the CDM are related in that both involve significant monetary flows to developing countries. In this paper, we want to examine whether membership on the EB significantly increases CDM acceptance rates.

As mentioned earlier, similar evidence exists for other international organizations. Membership on the UN Security Council increases aid flows from the U.S. (Kuziemko and Werker 2006) and credits from the World Bank and the IMF (Dreher et al. 2009a, 2009b). Apart from the simple effect of country membership in the Council, this also suggests the existence of wider political effects that extend to other international organizations. In our context, we may find interrelations between the EB and the World Bank. In particular, we will investigate whether the World Bank, as the predominant international player in the CDM market outside the UNFCCC, can make use of its lobbying expertise in influencing the EB's decisions.

The literature discussed so far is related to the EB in terms of decisions on financial flows to developing countries made by international organizations. Turning the focus away from the financial flows and more to the environmental good characteristic of the CDM, we lay out some possible similarities with decision making by national bureaucracies on environmental issues.

Cropper et al. (1992) investigate the determinants of U.S. EPA decision making on pesticide regulation. They find that risks to the environment and health increased the probability that the pesticide was forbidden. At the same time, larger benefits associated with the use of a pesticide and comments by grower associations on the need for it reduced this probability. Hird (1990) finds that the regional background of members on the congressional committee responsible for site cleanups only marginally influences the distribution of related funding. The main determinant of site cleanups seems to be their risk. Oates and Portney (2003) summarize these findings in the following way: Bureaucrats can be conceived as maximizing a weighted utility function of both social benefits and benefits that accrue to specific interest groups. We intend to extend this analysis to bureaucratic decision making in the framework of international agreements on global pollutants.

Studying the determinants of EB decision making can hence expand the knowledge of bureaucratic decisions on environmental issues to the international sphere and, more specifically, to committee membership in international organizations.

\subsection{Decision making in the EB}

According to the rules of the Kyoto Protocol, a CDM project may be accepted only if it generates emission reductions which are "additional" to reductions that would have happened without the CDM. For instance, if the investment in the replacement of an old power plant leads to higher energy efficiency and reduced emissions, this project does not automatically qualify for the CDM. If the replacement is economically attractive for mere efficiency reasons, the investment will take place without the CDM, and no CERs should be issued for it. 
However, any investor planning such a project has an obvious incentive in trying to argue that it is additional, because the CERs potentially generated can have a considerable financial value for him. For example, a wind power plant with an investment cost of 100 million $€$ in a moderately attractive wind regime could annually generate CERs of a value of six million $€$. In extreme cases (e.g., industrial gas projects), the value of CERs generated in a single year can even be a multiple of the initial investment cost. Thus, there is reason to believe that investors and other stakeholders are strongly interested in influencing EB decision making. ${ }^{1}$

While we argue for stakeholder interest, it may not yet be clear how this can effectively influence EB decision making. Following the rational choice approach employed by Frey (1984) and Vaubel (1991), we first define the relevant actors and then discuss plausible assumptions about their preferences, i.e., about the utility these actors derive from different decisions they might take. More specifically, we rely on Oates and Portney (2003) in imagining that EB members maximize a weighted utility function of both costs and benefits that accrue solely to their national constituencies, and costs and benefits that accrue globally, i.e., via climate change and mitigation. While non-additional CDM projects certainly lead to benefits for stakeholders in host and buyer countries, they can be regarded as a cost with respect to global greenhouse gas mitigation. Let us now consider the national stakeholder interests in more detail.

These interests may arise in different countries: the host countries, usually developing countries, but also including individual high-income countries like South Korea, and the buyer countries, which are industrialized countries with emission reduction targets as defined in Annex B of the Kyoto Protocol (Annex-B countries). The actual investor may be a national or international firm or a public institution. The project may be developed in the host country alone (unilateral CDM) or result from cooperation between a host and a buyer country investor.

If a project is registered by the EB and becomes operational, it generates CERs. In case of unilateral CDM the CERs can be sold by the host country investor at market prices, as no buyer country is directly involved in the project investment. Otherwise, the benefits arising from the CERs are shared between the host and the buyer country investors, whereby the shares depend upon the negotiation power of each party. The buyer country investor can then either also sell his part of the CERs on the market or use it to compensate his domestic emissions. In the case of bilateral CDM, the host country can also benefit from technology transfer.

The above discussion shows that both private investors and governments themselves may have an interest in their CDM projects being approved. As private firms cannot directly influence policy making at the international level, we assume that they will lobby their governments for support. In line with what is known on decision making in a possibly comparable international organization like the World Bank (Kaja and Werker 2009), we expect that countries directly represented among the ten members or ten alternates of the EB have a higher chance of influencing decision making in favor of their governments and private in-

\footnotetext{
${ }^{1}$ The potential influence of lobbying is further enhanced by the fact that additionality tests are far from straightforward. For example, projects can face political or other barriers and may therefore not be implemented without the CDM despite looking financially attractive. As these barriers cannot always be monetized, they may not be adequately considered. Figueres and Bosi (2006) discuss the problem of political barriers through the example of lighting projects. Major problems in this context are in particular distorted (i.e., low) electricity prices and poor recovery of cost, which taken together destroy any incentives for the consumer to buy more efficient light bulbs.
} 
vestors. While only the members have a formal right to vote, ${ }^{2}$ decisions are usually based on a consensus, so that alternates, who have the same right to participate in the debate, can be assumed to be similarly influential. Hence, we expect that EB decisions tend to favor projects and methodologies relevant for public and private investors in countries of EB members or alternates.

Moreover, not only investors can benefit from the CDM. In the last few years, the CDM has also become an important business for various kinds of consultancy and auditing services. There are consultancy services required for the development of project documentation, which is then to be audited ("validated") before a project may even request registration from the EB. Consultancy services are also required for the design of CDM methodologies. The organizations involved in this business are often private consultancy firms for which the success of getting a major project registered or of getting a methodology approved may be crucial for acquiring new orders in the future. We can therefore expect that these consultancies - just as private investors directly involved in CDM projects-will lobby their governments to ensure the success of their proposals. Therefore, we expect that if a consultant's country is an EB member, methodologies and projects are more likely to be accepted.

Finally, international organizations become involved in the process. They frequently act as an intermediate buyer pooling CDM projects to establish funds, with the resulting CERs equally benefiting all the members of the fund. The pioneer and most well-known example is the Prototype Carbon Fund (PCF) of the World Bank, operational since April 2000. The World Bank has opened up ten other funds since then (World Bank 2007, pp. 4-5). For the World Bank, this field represents a challenging new area of diversification. Of course, just as governments and private investors, the Bank is interested in positive EB decisions for its projects. First, it has to defend its image of a highly professional think tank in all areas of international development. And second, it might not be able to obtain subscriptions for new funds if projects in the portfolio of existing funds face difficulties in the registration process.

Moreover, international organizations compete with private consultancies in designing CDM methodologies. Again, the World Bank is at the forefront of activities in the area, and the stakes in favorable EB decisions on its methodologies are at least as high as for individual projects. Apart from the World Bank, the Asian Development Bank is involved in several CDM activities but only to a limited extent.

While international organizations are never directly represented by an EB member country, they may indirectly influence EB decisions. First, the methodologies and projects they develop are generally relevant for a number of countries, some of which will almost certainly be represented in the EB. Second, especially the World Bank as the predominant international organization involved in the field is present everywhere in the debates and has strong information and lobbying power. Finally, they may use networks within the international bureaucracies to reinforce their positions. It follows that if international organizations, i.e., the World Bank or the Asian Development Bank, are involved in the CDM process, methodologies and projects are more likely to be accepted.

In general, for most of the actors described above one might expect the interest in having methodologies passed to be even higher than the interest in the registration of individual projects. The reason is that there are fewer methodologies, and that each of the methodologies predetermines the CDM potential of a whole group of individual projects. At the same time, the stakes of individual countries in a given methodology depend on the geographical spread of the relevant technology. A methodology for hydro power, for instance,

\footnotetext{
${ }^{2}$ To date, a formal vote has only been made twice in the seven-year history of the EB.
} 
will be applicable in many countries, so that many countries will be similarly interested. A methodology for $\mathrm{N}_{2} \mathrm{O}$ reduction from adipic acid production, however, can be used only in China, South Korea, and Brazil because other countries do not apply this technology. The approval of methodologies relevant to technologies only in a small number of countries may benefit some countries (and/or their investors) to the detriment of others-as it can attract investment which substitutes for investment elsewhere. We therefore expect debates about this type of methodologies to be the most highly politicized, i.e., for these methodologies, EB membership should be particularly relevant.

We also expect some differences in the political interest in different type of projects. Here, however, interest can be assumed to simply depend upon project size. For small projects, even the official texts provide for a different treatment with faster procedures and fewer restrictions concerning project evaluation. Depending on project type, small projects have to meet one of the following thresholds: (i) renewable energy: $<15 \mathrm{MW}$; (ii) energy efficiency: $<60 \mathrm{GWh}$ (before December 2006: $<15 \mathrm{GWh}$ ); (iii) all other projects:

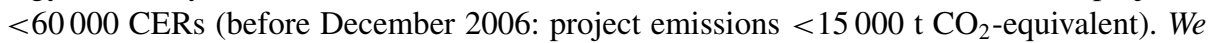
therefore expect higher chances of small projects being registered.

In contrast to other international organizations where the overriding dominance of individual member states is a frequently analyzed topic (see e.g., Fleck and Kilby 2006 for the World Bank or Barrow and Lee 2005 for the IMF), voting power is distributed equally over all members in the EB. Nevertheless, there could be differences in the effective influence an individual EB member may be able to exert. This influence may be related to the overall importance of a country which can raise its negotiating power (e.g., through informally linking up the issue at stake with cooperation or pressure in other fields). Moreover, it may be related to different levels of effort linked to a different strength of incentives. While all countries can benefit from the CDM, the potential for such benefits may be quite different. For instance, relatively more advanced developing countries, which are generally attractive for foreign direct investment (FDI), are usually also more attractive as host countries for the CDM (Michaelowa and Michaelowa 2007). On the buyer country side, it could be relevant which obligations for emission reductions the countries took up under the Kyoto Protocol and to what extent economic, technical and political constraints hinder them to meet these obligations domestically. Moreover, it may be relevant whether a country already has a strong position in FDI, which could enhance the potential interest for the CDM.

Similarly, even countries not represented in the EB may have higher chances to get their projects and methodologies adopted if they are generally powerful players, and if there is a high incentive for them to engage in influencing the decision-making process. Hence, for countries for which the CDM has a high potential, and for countries which are generally powerful players, we expect higher chances of methodology approval and project registration.

Turning our attention to the actual decision-making process of the EB, it may be worthwhile to note certain differences between project registration and methodology approval. As outlined already, the evaluation of whether a methodology is adequate to correctly calculate emission reductions and properly assess additionality, and whether a specific project meets these requirements, demands important technical knowledge which cannot be expected from EB members who are usually delegated from national bureaucracies. Special committees of researchers and other experts are therefore set in place to analyze these technical questions. The responsible technical committee for methodologies is the Methodology Panel (Meth Panel); for individual projects, it is the Registration and Issuance Team (RIT). Formally, both bodies have no decision-making power; all decisions are taken by the EB. While Meth Panel recommendations are reported in openly accessible minutes of the meeting, there is no 
transparency about RIT recommendations. In addition, positions on individual projects are exchanged in the EB behind closed doors despite the general rule that EB meetings should be public (UNFCCC 2006: p. 38, Decision 4/CMP.1, Annex I, rules 26 and 27).

In general, the extent to which EB members will favor political-economic over technical or scientific quality considerations must be expected to depend upon the above-described institutional setting of the decision-making process. In particular, the transparency of the process appears to be an important variable here. Many non-governmental organizations (NGOs) have taken a critical stance towards the CDM because they fear that CERs will be generated for projects that are neither additional nor sustainable (WWF 2007: p. 2; CDM Watch 2005). Clearly, under such conditions, a divergence between EB decision making and the technical advice of the relevant advisory committees will be closely scrutinized and may give raise to protests which could harm the image of the EB and the CDM as a whole. Obviously, NGO interventions are much easier when the information on both technical advice and EB decision making are openly available. Given the political cost of criticism, we may thus expect that interest related determinants of EB decision making-as opposed to technical or scientific considerations - will be stronger for decisions on projects than for decisions on methodologies.

Finally, it appears plausible to assume that it is in the joint interest of all actors potentially benefiting from the CDM to show that the mechanism works. Policy makers may also wish to show this, for the simple reason that they have taken a positive decision on the introduction of this market mechanism in the first place-a decision which would otherwise be considered by the general public as a failure. In order to show that the mechanism works in the first place, a certain volume of CDM activities is required, i.e., sufficient demand for $\mathrm{CDM}$ projects must be generated, and a relevant number of projects have to become operational. In the initial years, this may lead to a rather mild scrutiny of methodologies and projects submitted for registration. At the same time, in the long run, a decision-making body cannot always let everything pass if it wants to be taken seriously by any outside observer. In addition, the CDM may be rejected as a whole if the assessment procedure is deemed to be unreliable. Therefore, the selection process can be expected to become stricter over time.

\section{Data and estimation methods}

We assembled a dataset based on data from the UNEP Risoe Center (URC 2007) to empirically test our hypotheses. Our data contains qualitative information on the type and status of all projects and methodologies available on the CDM website of the UNFCCC on October 31, 2007. As we are interested in the determinants of EB decision making, we select only those cases where the status indicates that some EB decision has already been taken. This includes a total of 985 projects and 239 methodologies (including 31 afforestation and reforestation methods).

For these projects and CDM methodologies, the original UNEP Risoe Center dataset contains information on the host and (in case of multilateral CDM) the buyer countries, the names of the relevant consultancies or international organizations, the intermediate and final assessments of the EB, as well as the relevant dates for submission of and decisions on methodologies.

We expanded this dataset in many ways. First, we looked up the EB decision date for projects from individual project design documents (PDDs) available online (see UNFCCC 2007a). Then, we searched in the minutes of EB meetings (UNFCCC 2007b) for individual 
EB members and alternates in each year. Their nationality was then used to create dummy variables indicating host or buyer country representation in the EB. Using PDDs and relevant company websites, we also determined the country of the relevant consultants and equally created a dummy indicating EB membership.

Moreover, to capture the political relevance of a methodology, we created a categorical variable with ranges from 1 (applicability in all countries, i.e., low potential for political competition) to 5 (applicable only in a small number of countries, i.e., high potential for political competition). Thus, the higher the value of the variable, the higher is the political relevance of the decision.

Furthermore, we derived the gap between Annex B countries' Kyoto emission budgets and the projected emission levels during the commitment period. This variable indicates the expected need for CERs. For EU countries, it was based on forecasts by the EEA (2006), and for Canada and Japan on projections by the U.S. Department of Energy (2007) (only energy-related $\mathrm{CO}_{2}$ emissions). All remaining information was obtained through linear extrapolations based on UNFCCC inventory data for 2000-2005 (UNFCCC 2007c).

In addition, we merged this data with additional country information on GDP, FDI, trade, $\mathrm{CO}_{2}$ emissions, and education from the World Bank's (2006) World Development Indicators. All these variables are selected for the year 2000, which is the year just before CDM activities started in 2001, and therefore should be the year at which decision makers would orient themselves when considering the power of a country or the relevance of CDM as a complement to FDI. As the variation of this data over the years 2000 to 2006 is negligible when compared to the cross-country variation relevant here, and as information on these variables is taken into account with a lag which may vary from one EB member to the other, we consider that it is misleading to seek additional precision by entering this information for individual years of EB decision making. Using only information for the year 2000 also allows us to impute missing values with values for adjacent years. For tertiary education, for which information was missing for some developing countries even after this replacement procedure, additional linear imputations were made sequentially using secondary enrollment rates and GDP per capita.

The education variable might as well serve as proxy for the quality of projects and methodologies. As the RIT assessment is confidential and remains unpublished, an alternative quality control is particularly relevant in the context of projects, rather than methodologies. As discussed above, the Meth Panel assessment is available for methodologies, so that we can retrieve the relevant quality information from the individual meeting reports (UNFCCC 2007d).

At the project level, considering host country education levels alone may be one option, but does not seem sufficient to control for project quality. As an alternative, we therefore derive a new quality indicator based on a review of all 985 individual PDDs. Since one of the authors is himself a member of the RIT, he knows the standard criteria to be respected and carried out the results of all RIT assessments himself. The criteria include the credibility of the additionality test implemented by the project, as well as the correctness of the application of the baseline and monitoring methodology. Based on the information available from the PDDs, we define a categorical variable with categories from 1 (lowest quality) to 5 (highest quality) for each individual project.

To control for the quality of methodologies, we dispose of two alternative measures: the initial Meth Panel recommendation and the final Meth Panel recommendation. The initial recommendation corresponds to the first Meth Panel assessment prior to any discussion at the EB. If the following EB decision does not lead to a clear approval or rejection, the revised method is discussed in the Meth Panel again. 
The final Meth Panel recommendation is coded as a binary variable taking the value of 1 (method recommended) and 0 (method not recommended). The initial Meth Panel recommendation is coded as a categorical variable assigning 2 if an approval is recommended, 1 if changes are requested, and 0 if a rejection is recommended (corresponding to Meth Panel recommendation categories $\mathrm{A}, \mathrm{B}, \mathrm{C}){ }^{3}$ The initial Meth Panel recommendation therefore allows us to discriminate among good, intermediate, and bad methodologies.

We use a similar coding for our dependent variable, i.e., for EB decisions. Again, for methods we can distinguish three categories (immediately adopted: 2, adopted after revision: 1 , rejected or withdrawn: 0). Alternatively, we define a simple binary variable with the two categories "adopted" (1) and "rejected or withdrawn" $(0)$. For projects, the binary decision variable is coded in the same way. However, prior to the final decision there is a more detailed distinction possible between intermediate categories reflecting requested or imposed reviews as well as correction requests. The scale of the variable ranges from 4 (project registered) to 0 (project rejected or withdrawn).

The distribution of methodologies and projects into the different categories is presented in Table 1.

From Table 1 it becomes immediately apparent that decisions on methodologies have been stricter by far than decisions on individual projects. In fact, only $6 \%$ of all projects were rejected, whereas this was the case for $55 \%$ of the methodologies.

The estimation procedure is predetermined by the type of our dependent variables. For multivariate regressions with the binary and the other categorical variables we use probit and ordered probit regressions respectively. We initially also estimated logit and ordered logit models, but tests on the functional form indicated that the normal distribution yields a better fit.

We expect that observations on projects or methodologies of the same host countries may not be independent. Therefore, we explicitly take into account clusters at the host country level. One might also expect other limitations to the usual independence assumption. For instance, projects by the same buyer or validated by the same auditors may not be fully independent. However, for theoretical reasons (e.g., related to national technology) we expect this problem to be more relevant at the host country level. In addition, there is a large share of unilateral CDM for which buyer countries were not even defined when the EB decision was taken. To avoid an overly complex modeling framework with various overlapping clusters, we thus limit our analysis to the consideration of potential correlations within host countries.

\section{Empirical results}

\subsection{EB decisions on methodologies}

Let us first consider EB decision making with respect to CDM methodologies. Table 2 presents our regression results. In Regression 1, we use the binary final Meth Panel recommendation to control for the methodologies' quality. Note that the number of observations is lower for Regression 1 because for 20 methodologies no final Meth Panel recommendation has (yet) been made. This variable is highly significant and, in fact, explains almost all of

\footnotetext{
${ }^{3}$ In two exceptional cases, the initial Meth Panel recommendation is indecisive between B and C. We code these cases as 0.5 .
} 


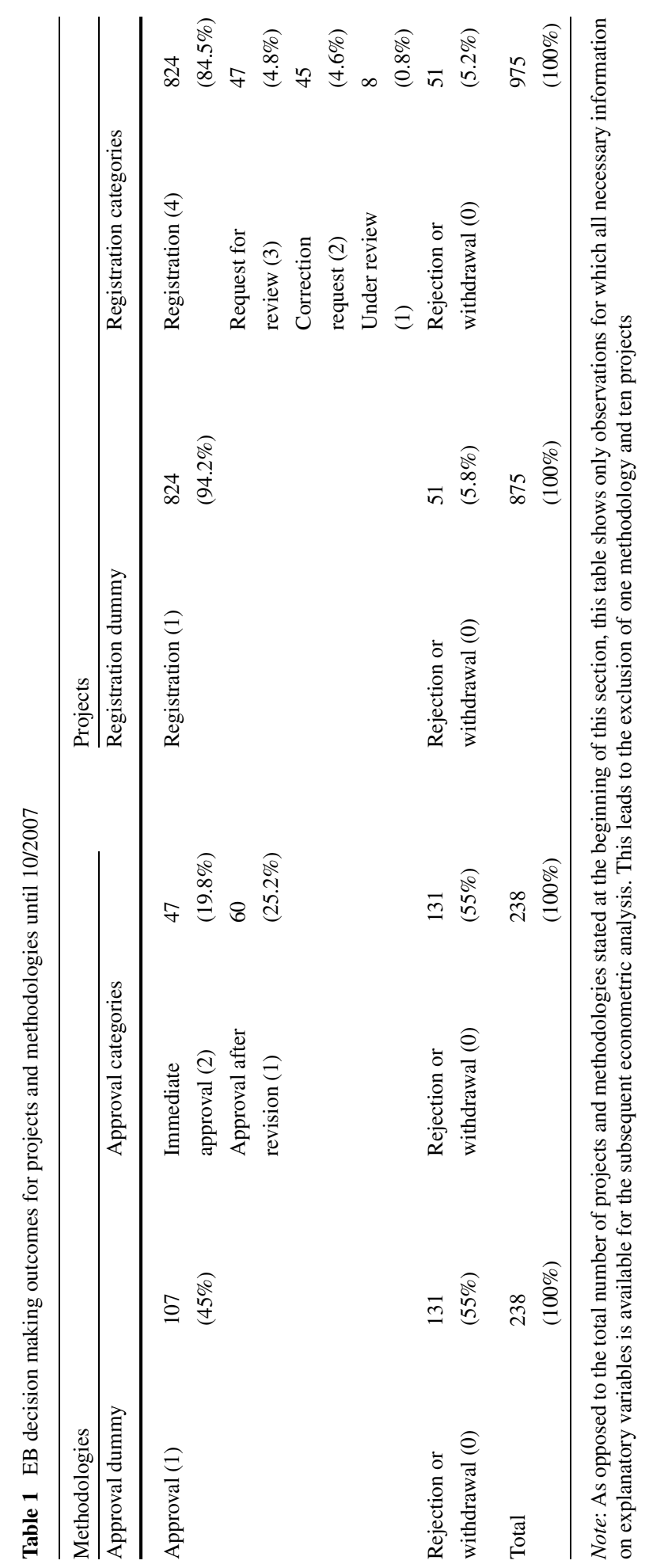


Table 2 Determinants of methodology approval by the CDM Executive Board

\begin{tabular}{|c|c|c|c|c|c|c|c|}
\hline & $\begin{array}{l}\text { (1) } \\
\text { Probit }\end{array}$ & $\begin{array}{l}\text { (2) } \\
\text { Probit }\end{array}$ & $\begin{array}{l}\text { (3) } \\
\text { Probit }\end{array}$ & $\begin{array}{l}\text { (4) } \\
\text { Probit }\end{array}$ & $\begin{array}{l}\text { (5) } \\
\text { Probit }\end{array}$ & $\begin{array}{l}\text { (6) } \\
\text { Probit }\end{array}$ & $\begin{array}{l}\text { (7) } \\
\text { Probit }\end{array}$ \\
\hline & $\begin{array}{l}\text { EB } \\
\text { approval } \\
\text { yes/no }\end{array}$ & $\begin{array}{l}\text { EB } \\
\text { approval } \\
\text { yes/no }\end{array}$ & $\begin{array}{l}\text { EB } \\
\text { approval } \\
\text { yes/no }\end{array}$ & $\begin{array}{l}\text { EB } \\
\text { approval } \\
\text { yes/no }\end{array}$ & $\begin{array}{l}\text { EB } \\
\text { approval } \\
\text { yes/no }\end{array}$ & $\begin{array}{l}\text { EB } \\
\text { approval } \\
\text { yes/no }\end{array}$ & $\begin{array}{l}\text { EB } \\
\text { approval } \\
\text { yes/no }\end{array}$ \\
\hline $\begin{array}{l}\text { Final Meth Panel } \\
\text { recommendation }\end{array}$ & $\begin{array}{l}4.87^{* * * *} \\
(0.00)\end{array}$ & & & & & & \\
\hline $\begin{array}{l}\text { Initial Meth Panel } \\
\text { recommendation }\end{array}$ & & $\begin{array}{l}3.03^{* * *} \\
(0.00)\end{array}$ & $\begin{array}{l}3.07^{* * *} \\
(0.00)\end{array}$ & $\begin{array}{l}3.05^{* * *} \\
(0.00)\end{array}$ & $\begin{array}{l}3.04^{* * *} \\
(0.00)\end{array}$ & $\begin{array}{l}3.07^{* * * *} \\
(0.00)\end{array}$ & $\begin{array}{l}3.05^{* * *} \\
(0.00)\end{array}$ \\
\hline $\begin{array}{l}\text { Host country is EB } \\
\text { member or alternate }\end{array}$ & $\begin{array}{c}0.31 \\
(0.17)\end{array}$ & $\begin{array}{l}0.58^{* *} \\
(0.01)\end{array}$ & & $\begin{array}{c}0.43 \\
(0.13)\end{array}$ & $\begin{array}{l}0.58^{* *} \\
(0.02)\end{array}$ & & $\begin{array}{l}0.45 \\
(0.15)\end{array}$ \\
\hline $\begin{array}{l}\text { Buyer country is EB } \\
\text { member or alternate }\end{array}$ & $\begin{array}{c}0.14 \\
(0.63)\end{array}$ & & $\begin{array}{c}0.52 \\
(0.12)\end{array}$ & $\begin{array}{c}0.22 \\
(0.59)\end{array}$ & & $\begin{array}{c}0.51 \\
(0.12)\end{array}$ & $\begin{array}{c}0.20 \\
(0.64)\end{array}$ \\
\hline $\begin{array}{l}\text { Consultant country is EB } \\
\text { member or alternate }\end{array}$ & $\begin{array}{c}0.14 \\
(0.69)\end{array}$ & $\begin{array}{r}-0.47 \\
(0.14)\end{array}$ & $\begin{array}{r}-0.47 \\
(0.14)\end{array}$ & $\begin{array}{r}-0.51 \\
(0.12)\end{array}$ & $\begin{array}{r}-0.48 \\
(0.14)\end{array}$ & $\begin{array}{r}-0.47 \\
(0.14)\end{array}$ & $\begin{array}{r}-0.52 \\
(0.12)\end{array}$ \\
\hline $\begin{array}{l}\text { Consultant is an } \\
\text { international } \\
\text { organization }\end{array}$ & $\begin{array}{c}0.45 \\
(0.47)\end{array}$ & $\begin{array}{l}0.87^{* *} \\
(0.03)\end{array}$ & $\begin{array}{l}0.92^{* *} \\
(0.03)\end{array}$ & $\begin{array}{l}0.89^{* *} \\
(0.04)\end{array}$ & $\begin{array}{l}0.90^{* * * *} \\
(0.01)\end{array}$ & $\begin{array}{l}0.93^{* * *} \\
(0.01)\end{array}$ & $\begin{array}{l}0.91^{* * *} \\
(0.01)\end{array}$ \\
\hline $\begin{array}{l}\text { Year of decisive EB } \\
\text { decision }\end{array}$ & $\begin{array}{c}-0.37^{* * *} \\
(0.00)\end{array}$ & $\begin{array}{c}-0.25^{* *} \\
(0.02)\end{array}$ & $\begin{array}{l}-0.26^{* *} \\
(0.02)\end{array}$ & $\begin{array}{l}-0.25^{* *} \\
(0.02)\end{array}$ & $\begin{array}{c}-0.24^{* *} \\
(0.04)\end{array}$ & $\begin{array}{c}-0.26^{* *} \\
(0.03)\end{array}$ & $\begin{array}{c}-0.24^{* *} \\
(0.05)\end{array}$ \\
\hline $\begin{array}{l}\text { FDI, net inflows into } \\
\text { host country } \\
\text { ( } 2000, \% \text { of GDP) }\end{array}$ & & & & & $\begin{array}{r}-0.01 \\
(0.92)\end{array}$ & $\begin{array}{r}-0.01 \\
(0.95)\end{array}$ & $\begin{array}{r}-0.01 \\
(0.94)\end{array}$ \\
\hline $\begin{array}{l}\text { FDI, net outflows from } \\
\text { buyer country } \\
(2000, \% \text { of GDP) }\end{array}$ & & & & & $\begin{array}{c}0.00 \\
(0.75)\end{array}$ & $\begin{array}{c}0.00 \\
(0.98)\end{array}$ & $\begin{array}{c}0.00 \\
(0.85)\end{array}$ \\
\hline Constant & $\begin{array}{c}738.95^{* * *} \\
(0.00)\end{array}$ & $\begin{array}{c}490.36^{* *} \\
(0.02)\end{array}$ & $\begin{array}{c}516.53^{* *} \\
(0.02)\end{array}$ & $\begin{array}{c}501.47^{* *} \\
(0.02)\end{array}$ & $\begin{array}{c}468.93^{* *} \\
(0.04)\end{array}$ & $\begin{array}{c}519.55^{* *} \\
(0.03)\end{array}$ & $\begin{array}{c}487.41^{* *} \\
(0.05)\end{array}$ \\
\hline Observations & 218 & 238 & 238 & 238 & 238 & 238 & 238 \\
\hline Log pseudolikelihood & -14.16 & -50.17 & -50.60 & -50.03 & -50.12 & -50.60 & -50.01 \\
\hline Wald $\chi^{2}$ & 186.53 & 62.35 & 69.76 & 81.54 & 158.73 & 183.03 & 189.46 \\
\hline Prob $>$ Wald $\chi^{2}$ & 0.00 & 0.00 & 0.00 & 0.00 & 0.00 & 0.00 & 0.00 \\
\hline Pseudo $R$-square & 0.91 & 0.69 & 0.69 & 0.69 & 0.69 & 0.69 & 0.69 \\
\hline Area under ROC curve & 0.99 & 0.97 & 0.97 & 0.97 & 0.97 & 0.97 & 0.97 \\
\hline
\end{tabular}

Notes: $p$-values in parentheses (adjusted for host country clusters). The Receiver-Operating Characteristic (ROC) curve jointly depicts the fraction of correctly identified positive values (approvals) and the fraction of correctly identified zero-values (rejections) for different cutoff points. The cutoff point specifies the minimum probability for a prediction of EB approval $=1$ (see, for example, StataCorp 2005, p. 85)

** Significant at 5\%; ${ }^{* * *}$ Significant at $1 \%$ 
Table 3 Final Meth Panel recommendation versus $\mathrm{EB}$ decision

\begin{tabular}{|c|c|c|c|}
\hline \multirow[t]{2}{*}{ Methpanel recommendation } & \multicolumn{3}{|c|}{ EB decision } \\
\hline & No & Yes & Total \\
\hline No & 122 & 1 & 123 \\
\hline Yes & 2 & 93 & 95 \\
\hline Total & 124 & 94 & 218 \\
\hline
\end{tabular}

the variation in our outcome variable. Table 3 shows a cross-tabulation of Meth Panel recommendations and EB decisions. This table demonstrates that, indeed, in only three cases the two committees show divergent views. Apparently, the EB decision is closely linked to the final Meth Panel recommendation. This implies that hardly any other variable has enough explanatory power to become significant. Only the year of the EB decision shows a significantly negative coefficient, indicating that $\mathrm{EB}$ decisions have become stricter over time. However, even this variable hardly adds any explanatory power to the overall model in Regression 1.

Considering initial rather than final Meth Panel recommendations and taking into account intermediate values between a clear yes or no (Regressions 2-7), we find more differences between the assessments of the two committees. There are divergent views in 26 cases, whereby the EB tends to be stricter than the Meth Panel (more negative assessments in 19 out of 26 cases).

Furthermore, looking more closely at EB membership, we find a very high correlation (0.71) between EB membership of the host and of the buyer country. This makes it difficult to distinguish between the effects of host and buyer country EB membership in a regression model including both variables. Therefore, these variables are estimated separately first (Regressions 2-3 and 5-6). In Regressions 4 and 7, it is tested whether despite their high correlation it still possible to estimate their effects jointly. The two sets of Regressions 2-4 and 5-7 only differ by the additional inclusion of FDI as a measure of a host country's CDM potential and buyer countries' propensity to invest abroad.

When we leave out buyer country EB membership and focus on host country EB membership alone (Regression 2) the coefficient indicates a significantly positive impact on methodology approval. Keeping all explanatory variables at their mean host country EB membership increases the predicted probability of a method to be approved by 22.6 percentage points. This result suggests that indeed EB decisions tend to favor methodologies relevant for EB member countries. When we focus on buyer country EB membership alone in Regression 3, it fails (marginally) to be significant at the $10 \%$ level. Finally, trying to estimate both the impacts of host and buyer EB membership jointly in Regression 4 increases the standard errors to such an extent that now even host country EB membership fails to be significant. However, as opposed to EB membership of the buyer country, host country membership is still relatively close to significant at the $10 \%$ level and also seems to be more important considering the size of the effect.

Moreover, we find significant coefficients for methodologies developed by international organizations (IO), i.e., predominantly the World Bank. The IO variable has the expected positive impact. IO participation increases the predicted probability of approval by 32.8 percentage points - at the mean of all explanatory variables, including the given level of technical and scientific quality as measured by the initial Meth Panel recommendation.

For consultants whose governments are represented in the $\mathrm{EB}$, the coefficient is negative and does not show any significant impact. As opposed to our hypothesis, it does not seem to matter for consultancies whether their country has a seat in the EB. 
The results above are robust to the inclusion of additional host and buyer country variables. We ran estimations with different possible controls from a selection of macro variables indicating the economic power and the CDM potential of host and/or buyer countries. None of them becomes significant or changes the coefficients of the other variables in any relevant way. As an example, Regressions 5-7 presents the results after control for FDI. Neither FDI inflows into the host country nor FDI outflows from the buyer country have any significant effect on methodology approval. Coefficients of all other variables are almost identical to those in Regressions 2-4.

All in all, Table 2 shows mixed evidence of the impact of political-economic, i.e., interestrelated variables on EB decisions on methodologies. We do find statistical and economic positive impacts of host country membership in the EB as well as of the consultant being an international organization - at least as soon as we control for effective quality with the initial Meth Panel recommendation. In line with our hypothesis, assessments become stricter over time. Nevertheless, the most dominant explanatory variable is our control for the effective quality of the methodology as indicated by the Meth Panel recommendation. Using the final Meth Panel recommendation, we hardly find any other significant result. Only using the initial Meth Panel recommendation, do all of the above mentioned political-economic variables become significant. If we believe the results using the initial Meth Panel recommendation, both technical and interest-related variables are simultaneously relevant to explaining EB decisions.

How can this difference between the impact of the initial and the impact of the final Meth Panel recommendation on the overall regression result be explained? It is likely that final Meth Panel recommendations are not free from political considerations. Indeed, even though the Meth Panel is a body of experts, it is not fully free from EB influence because the chair himself is an EB member, and there are frequent complaints from independent Meth Panel members about this linkage. Therefore, especially when the initial Meth Panel decision is not definitive, effective lobbying might concentrate on the Meth Panel. In fact, to some extent, final Meth Panel recommendations could anticipate the final EB decisions. If this were the case, final Meth Panel recommendations as used in Regression 1 would be endogenous and hence misleading as a control.

We dealt with this problem in various ways. First, we considered to instrument the quality of the methodology with host country tertiary education. However, the correlation between Meth Panel decisions and tertiary education was so low $(\rho=0.099)$ that we decided to abandon this approach. Second, we regressed the Meth Panel recommendation itself on the different political-economic variables introduced in Table 2. While using the final Meth Panel recommendation as the dependent variable leads to significant coefficients for most of these variables, this is not the case when using the initial Meth Panel recommendation. Hence, we consider that, as opposed to the final Meth Panel recommendation, the initial Meth Panel recommendation is a valid control variable for effective quality of methodologies. In turn, this substantiates the results of Regressions 2-7.

In our initial hypotheses, we had mentioned one more plausible effect which we have not discussed so far. This refers to the political relevance of the methodology in terms of its applicability to different countries. This variable does not have any significant effect in our regressions, so that we did not introduce it into Table 2. However, it seems to be related to the question whether there is at all a divergence between the initial Meth Panel recommendations and the $\mathrm{EB}$ assessments. In this context, the direction of the divergence does not seem to matter. Coding a simple dummy variable to indicate divergence and relating it to our variable for political variance in a bivariate logistic regression framework yields a (weakly) significant odds ratio of 1.82 ( $p$-value $=0.105$, regression not reported here). 
This implies that the more limited the applicability of the methodology, i.e., the higher the competition effect and thus the political relevance, the higher the chances that some divergence of views arises in the first place.

Finally, we checked the robustness of the positive impact of EB membership in two ways (regressions not reported here). First, we introduced linear country fixed effects for Regressions 2-7 to remove any unobserved heterogeneity on the country level using the MundlackChamberlain approach (Wooldridge 2002: pp. 487-490). The effect of EB membership does not disappear. Second we tried to examine more directly whether the effect of country membership might be confounded with the (unobserved) capacity of a country to develop sound CDM methodologies. To do so, we introduced variables for pre- and post-EB membership. If there were any stable latent variables that would drive the results, pre- and/or post-EB membership should also be significant. We do not find any sign of significant pre- or postEB membership. Hence, all in all, we are confident that no unobserved latent variables are driving the results.

Summing up our discussion of decision making on methodologies, we can say that there is some relevance of political-economic, i.e., non-quality related, but interest-driven variables. There is clear evidence that — conditional on the initial Meth Panel recommendationhost country EB membership as well as the World Bank influence have a positive impact on the approval of a methodology. Moreover, as expected, decisions have become stricter over time. At the same time, we do not find the expected effects for buyer country EB membership or consultant country EB membership. Moreover, EB decisions closely follow Meth Panel recommendations, indicating a strong effect of quality after all. In fact, most of the time EB members do not tend to decide in their own favor or in favor of their constituencies. There is some evidence for an effect of the political relevance of the methodology on whether or not there is a divergence of views between the Meth Panel and the EB. Moreover, methodologies for which the EB cannot find a clear decision immediately seem to be the prime target of lobbying activities. Especially in these cases, final Meth Panel decisions also appear to be affected by this lobbying influence.

\subsection{EB decisions on individual projects}

We will now analyze EB decisions on individual projects, where the transparency of the decision-making process is more limited, and see how these deviate from decisions on methodologies. In particular, we note that there are only a small number of rejections as compared to methodologies. Only $5.8 \%$ of all projects, for which a final decision had been taken until October 31, 2007, have been rejected.

In fact, various explanatory variables related to EB membership cannot even be introduced into our multivariate regressions because there is no variance in outcomes. Thus, all 29 projects for which the World Bank was the credit buyer successfully achieved their registration. Similarly, in all 15 cases in which the host country was represented as an alternate EB member, the corresponding projects were registered. And finally, in all 7 cases in which the validator's government was represented in the EB, projects were registered, too.

Moving beyond descriptive statistics we present the results of our more general econometric assessment in Table 4. Even though the rejection rate is relatively small, we stick to traditional probit estimations. An alternative procedure could be to explicitly consider our data as rare events data and to carry out a case control study which introduces a selection on the dependent variable prior to estimation and tends to perform better in Monte Carlo simulations (King and Zeng 2001). However, this procedure is generally suggested only for datasets in which one of the two occurrences is below $5 \%$ and in which the total number of observations is relatively small. 


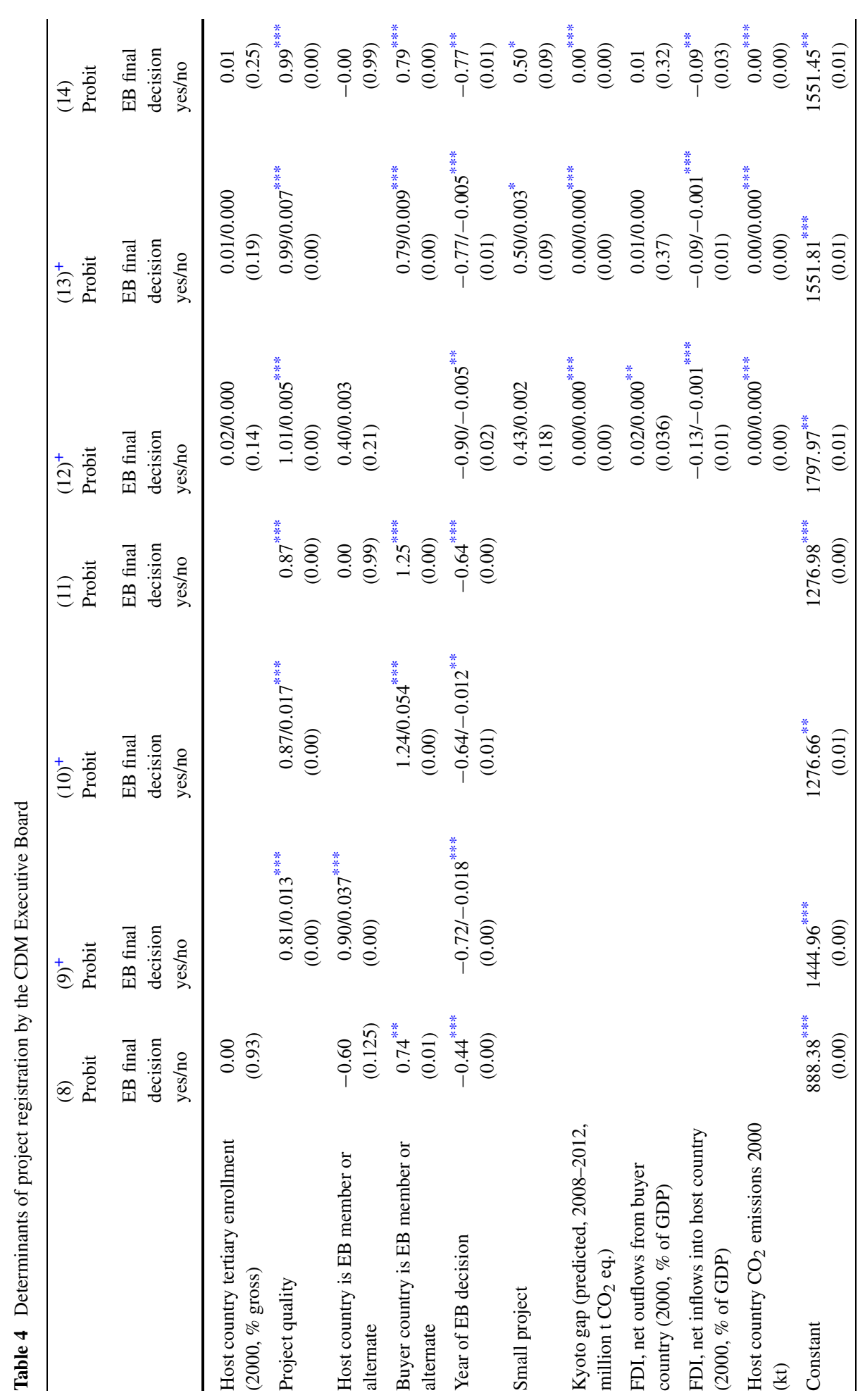




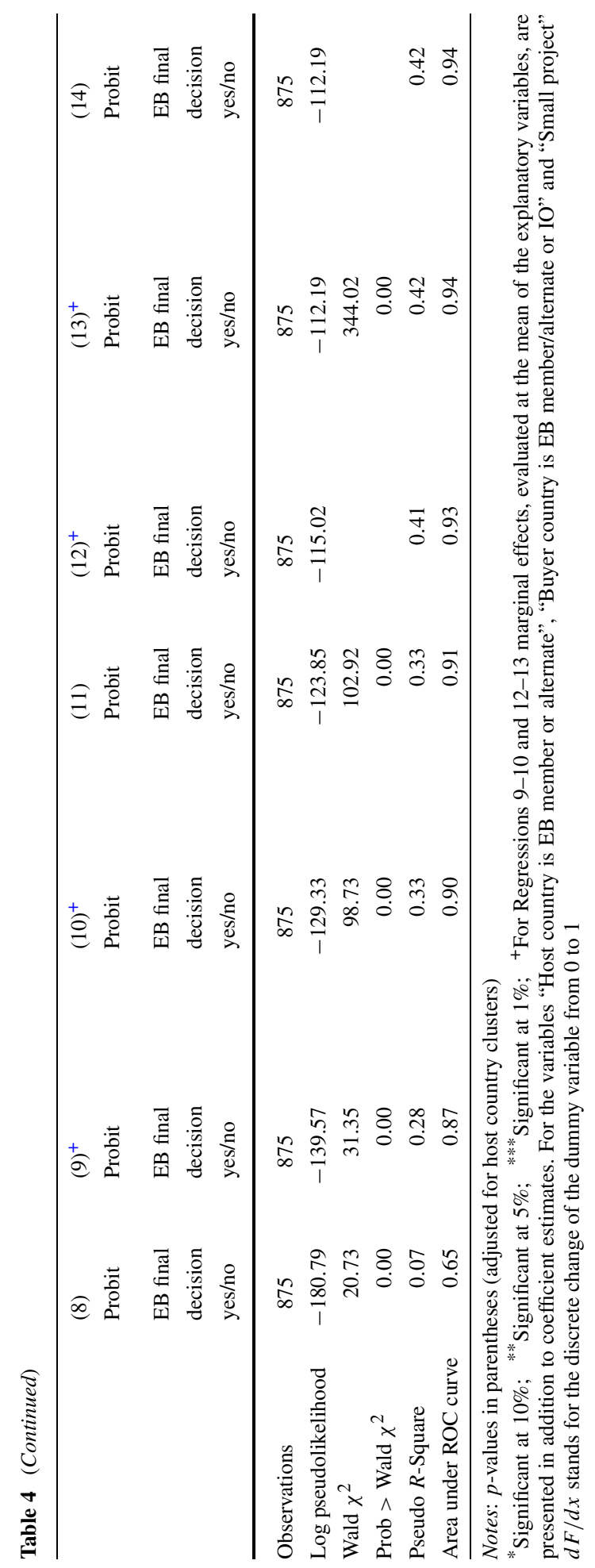


One of the major econometric concerns is how to properly control for the effective quality of a project. Using host country tertiary enrollment rates as a proxy (Regression 8) does not show any significant relationship with EB decision making-a result which leaves us with some doubts about the adequacy of this variable for this purpose, and thus about this regression specification as a whole. Measures of fit for the overall regression are very low, too. In all other regressions, we use the assessment of project quality in line with RIT criteria as described in Sect. 3. This variable is highly significant throughout all further models (Regressions 9 to 14) and considerably increases their fit. It seems to capture the actual effect of quality rather well.

Host country EB membership mostly shows the expected positive coefficient, which, however, becomes only significant in Regression 9 where buyer country EB membership is not considered. Just as in the case of methodologies, the estimation problem here is a very high correlation between both membership variables $(0.77)$. We therefore consider the effects again first individually and then combined.

Buyer country EB membership turns out to be always positively significant. Its effect also remains unaffected by the simultaneous introduction of host country membership. The stronger factor in terms of EB membership, therefore, appears to be membership of the buyer. Marginal effects displayed in Regression 10 suggests that buyer country membership increases the predicted probability of a project to be registered by about 5.4 percentage points (evaluated at the mean of the explanatory variables). This is a rather small effect in terms of its absolute value. The size of the effect is reduced even further when other host country variables are taken into account (see Regressions 13 and 14). ${ }^{4}$ One should note, however, that the overall registration rates are very high. Hence, marginal effects (as well as the effects for the discrete change of the dummy variable from 0 to 1) are estimated to be fairly small, even though they are highly significant in statistical terms.

Our results on project registration confirm the earlier result for methodologies that EB decisions have become stricter over time. This result is highly significant across all regression specifications. Moreover, in Regressions 12 to 14, we find some evidence for the importance of variables indicating the economic relevance of the project-in general, as well as for the host or buyer country individually. With respect to project size, our hypothesis suggested that small projects would not lead to relevant competition effects. Hence, we expected them to be registered more easily. Indeed, Regressions 13 and 14 show that small projects have a significantly higher chance to be registered.

Moreover, as expected, the potential demand for certified emission reductions affects EB decisions. If a buyer country's Kyoto gap is large, i.e., its need for the CDM is high, its chances to have its projects registered by the EB increase. Finally, we look at the potential supply of certified emission reductions. The overall amount of $\mathrm{CO}_{2}$ emissions of a host country, which relates to the economic potential of the CDM, is also positively related to projects being registered.

There is only one political-economic variable with a coefficient that contradicts our initial expectations. We supposed that host country FDI inflow, indicating host country attractiveness for investments, would affect project registration positively. However, we find a significant negative effect. Most plausibly, this can be explained by the relevance of the unilateral CDM. Unilateral CDM may open up new possibilities for countries willing to attract a higher share of international investment but not yet achieving this goal. An example could be India where, at the turn of the century, FDI and trade involvement were relatively limited

\footnotetext{
${ }^{4}$ Only the coefficient of the constant is very high. However, this is simply a result of the range of the "year" variable.
} 
but which is opening up and can now make use of the unilateral CDM as some kind of a marketing tool to attract more FDI in the future.

Comparing the different regression specifications, the best fit of the data to the model is achieved in Regressions 13 and 14. In these regressions, EB membership, the variables relating to the economic potential of projects, and the effective quality control variable explain EB decision making rather well. We are confident that these explanatory variables cover the most important determinants of EB decision making. Ramsey's Reset tests ${ }^{5}$ for the probit models in Table 4 are satisfactory. For all regressions, the squared predicted values are never significant (not even at the $10 \%$ level) while the plain predicted values are highly significant. Leaving out the political-economic variables, the test indicates that important information is missing.

Furthermore, we applied similar robustness checks to the regressions on projects as we did before to the regressions on methodologies. Controlling for unobserved heterogeneity via linear methodology fixed effects does not change the results. Neither do pre- or post-EB membership turn up significantly.

Summing up our discussion of individual project decisions, we find non-negligible evidence for almost all of our initial political-economic hypotheses. Although results are not always significant in all relevant specifications and the size of the effects is often rather small, the overall picture provides a rather convincing evidence of the relevance of various stakeholder-related factors for EB decision making. Especially with respect to buyer country EB membership, the results show that individual projects are subject to political influence in general. In addition, some other relevant political-economic variables could not even be introduced into our regression models as they perfectly predicted success.

The overall picture of political-economic influence may be seen as more consistent here than in the context of EB decisions on methodologies. This in turn is in line with our hypothesis that due to the lack of transparency for decisions on individual projects, politicaleconomic factors matter more for EB decisions on individual projects than for decisions on methodologies. Obviously, given the high overall registration rates for CDM projects, the absolute value of the observed marginal effects is much lower for projects. Finally we observe that along with political-economic considerations, for projects just as for methodologies, the impact of quality on EB decisions is also very strong.

\section{Conclusions}

In this paper, we set out to examine what determines decision making on the CDM Executive Board. Based on prior studies of decision making in international organizations, we considered that EB members maximize a weighted utility function of global and country specific costs and benefits. Theoretically, EB decisions should hence be influenced not only by the technical quality of the methodology or project under consideration, but also by the special interest of various stakeholders, which in turn seek the support of their country representatives. This led us to expect that membership on the EB should have a positive impact on methodology approval and project registration. Furthermore, we expected that World Bank involvement would also raise the chances of acceptance. If methodologies are only

\footnotetext{
${ }^{5}$ In the basic version of Ramsey's Reset test which is used here, the dependent variable is regressed on its own predicted values from the main regression and their squares. If the initial model is well specified, the coefficient of the predicted values should be highly significant, while the square term should not contain any additional information and thus be insignificant.
} 
beneficial for a few countries, we expected more politicized decisions and hence more divergence from recommendations by the Methodology Panel. In turn, for small projects, for which there is less scrutiny with respect to registration, higher chances of registration were expected. Turning to the stakes actually involved, more powerful countries and countries with high CDM potential were thought to be more successful in methodology approval and project registration. As there is less transparency in the assessment process of projects than of methodologies, we expected stronger results for all political-economic factors on the former. Finally, we argued that decisions should become stricter over time, as a certain number of effectively registered CDM projects were required to show that the whole mechanism might actually work.

Based on our econometric analysis on the determinants of EB decision making over almost 1000 individual CDM projects and 250 methodologies, we find that the EB is strongly committed to quality criteria. Recommendations by the Methodology Panel explain a large part of EB methodology approval. Project quality is just as important a determinant for project registration by the EB. At the same time, our results suggest that a number of political-economic variables also drive outcomes of EB decision making.

More specifically, we find that EB decisions tend to favor projects relevant for EB member countries. This is the case for both host and buyer countries, whereby the role of the latter is more clearly significant for project registration. For methodologies, only the host country influence is significant in the regressions presented here. However, this is partly driven by a high correlation between host and buyer countries which makes it difficult to disentangle these effects. While EB membership is generally highly relevant, consultancies (as opposed to investors) active in the CDM market do not seem to benefit from the influence of their country representatives.

For projects and methodologies alike, the involvement of the World Bank as a powerful international player improves the probability of success. In addition, as expected, we observe more divergence from Meth panel recommendations for those methodologies which are relevant only for a limited number of countries. Moreover, project regressions clearly show that small projects are registered more easily, i.e., without much critical discussion.

There is mixed evidence for our hypothesis that countries for which the CDM has a high potential and countries which are generally powerful players have a higher chance to see their projects and methodologies accepted by the EB. For CDM projects we observe that host countries with a high overall level of $\mathrm{CO}_{2}$ emissions (and thus a high potential for CDM investments) are able to obtain registration for a higher share of their projects. At the same time, host FDI inflows or other indicators of economic attractiveness and power do not improve the probability of projects being registered. For methodologies FDI inflows do not show the expected positive effect, either. On the contrary, it seems that to some extent CDM even substitutes for FDI.

The effect of transparency of the decision-making process could not directly be tested, but there are some indications for its relevance when comparing the assessment process for projects and methodologies. In particular, project registration rates are generally much higher than rates for methodology approval. However, political-economic considerations are clearly significant in both contexts and not substantially stronger in the less transparent decision-making process on individual projects.

Finally, for both methodologies and projects, there is highly consistent evidence that EB decision making has become stricter over time-along with the increase in the stock of methodologies and projects already approved.

As the EB is a rather new institution, its functioning may still be subject to change. This eventually leads us to reflect upon potential institutional improvements, which our analysis 
may suggest. First, it has to be recalled that the existing system seems to function rather well. This is the case because the predominant determinant of EB decisions appears to be quality. Nevertheless, the impact of the political-economic variables is clearly significant. Let us consider the potential relevance of these variables in the context of institutional reform.

Time dependency, in the sense that initially EB decision making tended to be less strict than in more recent times, does not seem to present any further problem for the future. Now that the CDM has become a widely used mechanism, no fall-back has to be expected.

The influence of IOs and of other economic and EB membership variables can, however, give rise to some concern. With respect to methodologies, potential lobbying after initial decisions for revision calls for further analysis. If necessary, institutional safeguards have to be put in place to limit the impact of lobbying. An additional recommendation for the procedure on registration of individual projects could be to increase transparency. This would also imply a publication of the initial scientific or technical assessments of the RIT.

Acknowledgements Helpful comments by Thomas Bernauer, Simon Hug, Thomas König, Ulrich Oberndorfer, Jeremy Tobacman and participants of the CIS/KOF conference on the Political Economy of International Organizations (PEIO) in Ascona, 3-8 February 2008, as well as of the 16th Ph.D. Workshop on International Climate Policy at the ZEW in Mannheim, 1-2 May 2008, are gratefully acknowledged.

\title{
Appendix A. Annex 1: Rules on the transparency of EB decision making
}

\author{
E. Transparency-Rule 26
}

Subject to the need to protect confidential information, the principle of transparency should apply to all the work of the Executive Board, encompassing the timely public availability of documentation and channels through which external comments by all Parties and all UNFCCC accredited observers and stakeholders can be submitted for consideration by the Board. The posting of the Board's meetings on the Internet is one way to ensure transparency.

\section{F. Attendance-Rule 27}

Paragraph 16 of the CDM modalities and procedures:

1. Meetings of the Executive Board shall be open to attendance, as observers, by all Parties and by all UNFCCC accredited observers and stakeholders, except where otherwise decided by the Executive Board.

2. In the context of paragraph 1 above, the Executive Board may decide, in the interest of economy and efficiency, to limit attendance at its meetings to members, alternate members and secretariat support staff. In such instances, the Executive Board shall take all practicable steps to accommodate in other ways the interests of Parties, non-Parties to the Kyoto Protocol that are Parties to the Convention and accredited UNFCCC observers and stakeholders to observe its proceedings, except when the Executive Board decides to close all or a portion of a meeting.

Source: UNFCCC 2006: Decision 4/CMP.1, Annex I, rules 26 and 27, p. 38. 


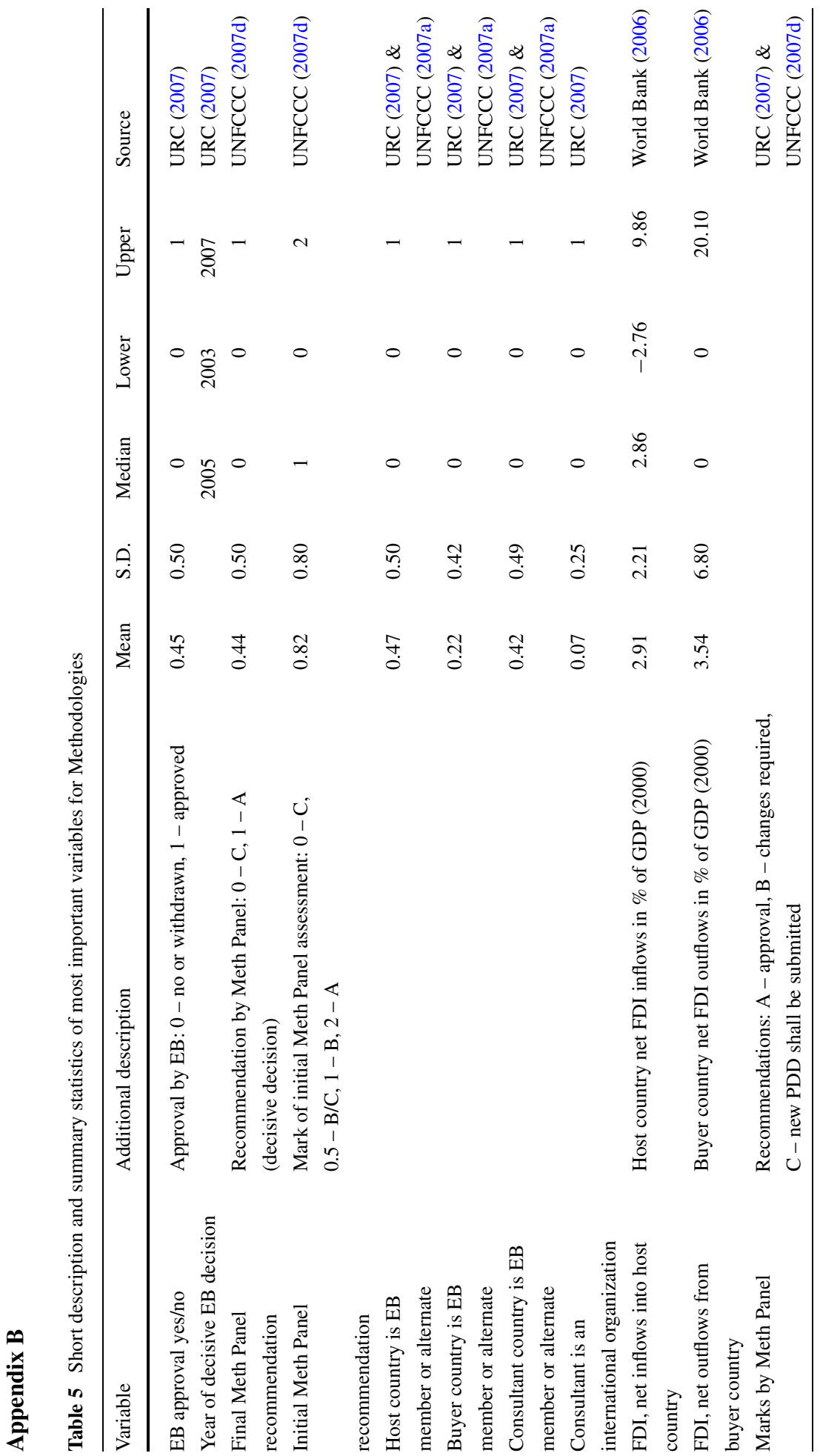




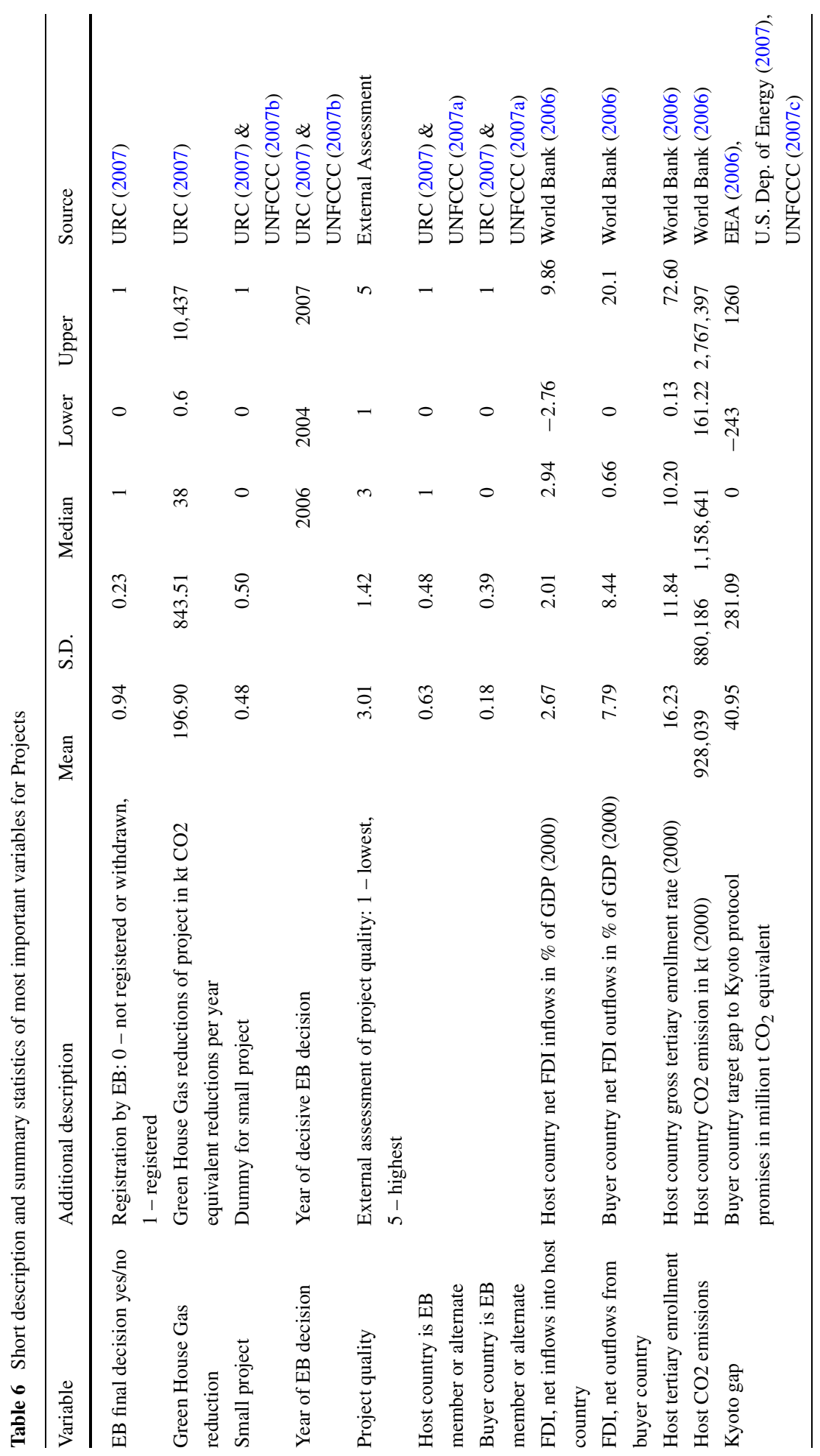




\section{References}

Barrow, R., \& Lee, J.-W. (2005). IMF programs: who is chosen and what are the effects? Journal of Monetary Economics, 52(7), 1245-1269.

CDM Watch (2005). Der Clean Development Mechanism (CDM) als Option in der Klimapolitik der Schweiz [The CDM as an option in Swiss climate policy]. Study commissioned by Greenpeace. http://www.greenpeace.ch/fileadmin/user_upload/Downloads/de/Klima/cdm_studie.pdf. Accessed 23 January 2008.

Cropper, M. L., Evans, W. N., Beradi, S., Ducla-Soares, M. M., \& Portney, P. R. (1992). The determinants of pesticide regulation: a statistical analysis of EPA decision making. Journal of Political Economy, 100(1), 175-197.

Dreher, A., Sturm, J.-E., \& Vreeland, J. R. (2009a). Global horse trading: IMF loans for votes in the United Nations Security Council. European Economic Review, 53(7), 742-757.

Dreher, A., Sturm, J.-E., \& Vreeland, J. R. (2009b). Development aid and international politics: does membership on the UN Security Council influence World Bank decisions? Journal of Development Economics, $88,1-18$.

European Environment Agency (2006). Greenhouse gas emission trends and projections in Europe 2006. Copenhagen: EEA Report 9/2006.

Figueres, C., \& Bosi, M. (2006). Achieving greenhouse gas emission reductions in developing countries through efficient lighting projects in the Clean Development Mechanism. Mimeo. Washington: The Carbon Finance Unit at the World Bank.

Fleck, R., \& Kilby, C. (2006). World Bank independence: a model and statistical analysis of U.S. influence. Review of Development Economics, 10(2), 224-240.

Frey, B. S. (1984). The public choice view of international political economy. International Organization, 38(1), 199-223.

Frey, B. S. (1997). The public choice of international organizations. In D. C. Mueller (Ed.), Perspectives on public choice. Cambridge: Cambridge University Press.

Hird, J. A. (1990). Superfund expenditures and cleanup priorities: distributive politics or the public interest? Journal of Policy Analysis and Management, 9(4), 455-483.

Kaja, A., \& Werker, E. (2009). Corporate misgovernance at the World Bank. Harvard Business School Working Paper, 09-108.

King, G., \& Zeng, L. (2001). Logistic regression in rare events data. Political Analysis, 9(2), 137-163.

Kuziemko, I., \& Werker, E. (2006). How much is a seat on the Security Council worth? Foreign aid and bribery at the United Nations. Journal of Political Economy, 114(5), 905-930.

Michaelowa, A., \& Michaelowa, K. (2007). Climate or development: is ODA diverted from its original purpose? Climatic Change, 84(1), 5-22.

Oates, W. E., \& Portney, P. R. (2003). The political economy of environmental policy. In K. G. Mäler \& J. R. Vincent (Eds.), Handbook of environmental economics, vol. 1 (pp. 325-354). Amsterdam: Elsevier.

Sandler, T. (1992). Collective action. Theory and applications. New York: Harvester Wheatsheaf.

Sandler, T., \& Hartley, K. (2001). Economics of alliances: the lessons for collective action. Journal of Economic Literature, 39, 869-896.

StataCorp (2005). Logistic postestimation. In StataCorp, Stata base reference manual, volume 2, K-Q, release 9 (pp. 69-92). College Station: Stata Press.

UNFCCC (2002). Report of the Conference of the Parties on its seventh session, held at Marrakesh from 29 October to 10 November 2001. Addendum. Part two: action taken by the Conference of the Parties, volume II, paragraph 43. FCCC/CP/2001/13/Add.2. Bonn: UNFCCC.

UNFCCC (2006). Report of the Conference of the Parties serving as the meeting of the Parties to the Kyoto Protocol on its first session, held at Montreal from 28 November to 10 December 2005. Addendum. Part two: action taken by the Conference of the Parties serving as the meeting of the Parties to the Kyoto Protocol at its first session. FCCC/KP/CMP/2005/8/Add.1. Bonn: UNFCCC.

UNFCCC (2007a). Project activities. http://cdm.unfccc.int/Projects/index.html. Accessed 23 January 2008.

UNFCCC (2007b). EB meetings. http://cdm.unfccc.int/EB/index.html. Accessed 23 January 2008.

UNFCCC (2007c). GHGs without LULUCF. http://unfccc.int/files/ghg_emissions_data/applications/X-zipcompressed/ai_total_wolulucf.zip. Accessed 23 January 2008.

UNFCCC (2007d). Baseline and monitoring methodologies. http://cdm.unfccc.int/methodologies/index.html. Accessed 23 January 2008.

URC (2007). Welcome to the UNEP Risoe CDM/JI pipeline analysis and database. http://www. cdmpipeline.org. Accessed 5 November 2007.

U.S. Department of Energy (2007). Energy information administration, international energy outlook 2007. Washington: U.S. Department of Energy.

Vaubel, R. (1986). A public choice approach to international organization. Public Choice, 51, 39-57. 
Vaubel, R. (1991). The political economy of the International Monetary Fund: A Public Choice analysis. In R. Vaubel \& T. D. Willet (Eds.), The political economy of international organizations. A public choice approach. Boulder: Westview Press.

Vaubel, R. (2006). Principal-agent problems in international organizations. Review of International Organizations, 1(2), 125-138.

Vaubel, R., \& Willet, T. D. (1991). The political economy of international organizations. A public choice approach. Boulder: Westview Press.

Wooldridge, J. F. (2002). Econometric analysis of cross section and panel data. Cambridge: MIT Press.

World Bank (2006). World development indicators, CD Rom. Washington: World Bank.

World Bank (2007). Carbon finance for sustainable development 2007. Washington: World Bank.

WWF (2007). WWF background note to the report "Is the CDM fulfilling its environmental objectives? An evaluation of the CDM and options for improvement" prepared for WWF by the Öko-Institut November 2007. Berlin: WWF. http://assets.panda.org/downloads/cdm_report_wwf_background_paper.pdf. Accessed 23 January 2008. 